\title{
Reabilitação proprioceptiva em lesão de lca associado a menisco medial
}

\author{
Proprioceptive rehabilitation in acl injury associated with medial menisco \\ Rehabilitación propioceptiva en lesión del lca asociada con menisco medial
}

Recebido: 02/09/2021 | Revisado: 11/09/2021 | Aceito: 15/09/2021 | Publicado: 17/09/2021

Emanuel Osvaldo de Sousa

ORCID: https://orcid.org/0000-0003-2825-4275 Universidade Estadual do Piauí, Brasil

E-mail: emanfisio@hotmail.com

Lucas Gabriel de Araújo Marcião

ORCID: https://orcid.org/0000-0002-2592-8644

Centro Universitário da Amazônia, Brasil

E-mail: lucasgabrielaraujomarciao90@gmail.com

João Felipe Tinto Silva

ORCID: https://orcid.org/0000-0003-3662-6673

Centro Universitário de Ciências e Tecnologia do Maranhão, Brasil

E-mail: felipetinto99@gmail.com

Antonia Claudiana Batista da Silva Melo

ORCID: https://orcid.org/0000-0003-1261-7342

Universidade Estadual do Piauí, Brasil

E-mail: wilner_claudiana@hotmail.com

Laíla de Lara Vasconcelos Carvalho

ORCID: https://orcid.org/0000-0001-7510-1445

Faculdade Integral Diferencial, Brasil

E-mail: lailadelarafisio@gmail.com

Diego Bruno Brito Cerqueira

ORCID: https://orcid.org/0000-0002-8083-1634 Faculdade Integral Diferencial, Brasil

E-mail: diegocerqueirafisioterapeuta@hotmail.com

Ana Lys Marques Feitosa

ORCID: https://orcid.org/0000-0003-2004-6279 Universidade Federal do Piauí, Brasil

E-mail: anallys@gmail.com

\begin{abstract}
Resumo
A articulação do joelho é uma estrutura formada pela união de três ossos: fêmur, tíbia e patela (osso sesamóide). Em geral, o joelho consiste em uma complexa estrutura óssea, articular, ligamentar, capsular, meniscal e muscular, sendo capazes de promover estabilidade e mudar de uma estrutura flexível as irregularidades do solo, para uma rígida de sustentação de peso. A estabilidade do joelho é dada pelo mecanismo contensor dos ligamentos cruzado anterior e posterior, ligamentos colateral medial e lateral, sendo primordiais para uma eficiente locomoção humana. Refere-se a um estudo foi realizado sobre o tema através de referências bibliográficas nacionais e internacionais, periódicos, livros, jornais e revistas científicas. As buscas selecionadas foram decorrentes do ano de 1992 a 2011, e que estavam disponíveis para acesso on-line. Os artigos selecionados foram avaliados pelo autor da pesquisa, e aqueles que não se enquadravam no tema proposto foram desconsiderados. Os sinais e sintomas das lesões ligamentares do joelho variam de acordo com o mecanismo causador, a gravidade da lesão, os tecidos acometidos e a extensão do acometimento. Geralmente são evidentes graus variáveis de dor, derrame articular, insegurança e incapacidade. Conclui-se com base no estudo realizado, constatou-se que de acordo com os autores investigados, os treinamentos proprioceptivos são eficientes na reabilitação da lesão de ligamento cruzado anterior e menisco lateral, promovendo assim, melhora da estabilidade e capacidade funcional, proporcionando precocemente maior segurança e retorno as atividades da vida diária de forma satisfatória.
\end{abstract}

Palavras-chave: Reabilitação proprioceptiva; Ligamento cruzado anterior; Meniscos Tibiais.

\section{Abstract}

The knee joint is a structure formed by the union of three bones: femur, tibia and patella (sesamoid bone). In general, the knee consists of a complex bone, articular, ligament, capsular, meniscal and muscular structure, capable of promoting stability and changing the ground irregularities from a flexible structure to a rigid one for weight-bearing. Knee stability is provided by the restraining mechanism of the anterior and posterior cruciate ligaments, medial and lateral collateral ligaments, which are essential for efficient human locomotion. It refers to a study carried out on the subject through national and international bibliographical references, periodicals, books, newspapers and scientific journals. The selected searches were from 1992 to 2011, and were available for online access. The selected articles were 
evaluated by the author of the research, and those that did not fit the proposed theme were disregarded. Signs and symptoms of knee ligament injuries vary according to the causative mechanism, the severity of the injury, the tissues involved and the extension of the involvement. Variable degrees of pain, joint effusion, insecurity and disability are usually evident. In conclusion, based on the study carried out, it was found that, according to the authors investigated, proprioceptive training is efficient in the rehabilitation of anterior cruciate ligament and lateral meniscus injuries, thus promoting improved stability and functional capacity, providing early improvement. safety and return to activities of daily living in a satisfactory manner.

Keywords: Proprioceptive rehabilitation; Anterior cruciate ligament; Menisci Tibial.

\section{Resumen}

La articulación de la rodilla es una estructura formada por la unión de tres huesos: fémur, tibia y rótula (hueso sesamoideo). En general, la rodilla está formada por una compleja estructura ósea, articular, ligamentaria, capsular, meniscal y muscular, capaz de promover la estabilidad y cambiar las irregularidades del suelo de una estructura flexible a una rígida para soportar peso. La estabilidad de la rodilla es proporcionada por el mecanismo de restricción de los ligamentos cruzados anterior y posterior, ligamentos colaterales medial y lateral, que son esenciales para la locomoción humana eficiente. Se refiere a un estudio realizado sobre el tema a través de referencias bibliográficas, publicaciones periódicas, libros, diarios y revistas científicas nacionales e internacionales. Las búsquedas seleccionadas fueron de 1992 a 2011 y estaban disponibles para acceso en línea. Los artículos seleccionados fueron evaluados por el autor de la investigación y se descartaron aquellos que no se ajustaban al tema propuesto. Los signos y síntomas de las lesiones de los ligamentos de la rodilla varían según el mecanismo causante, la gravedad de la lesión, los tejidos afectados y la extensión de la afectación. Suelen ser evidentes grados variables de dolor, derrame articular, inseguridad y discapacidad. En conclusión, con base en el estudio realizado, se encontró que, según los autores investigados, el entrenamiento propioceptivo es eficiente en la rehabilitación de lesiones del ligamento cruzado anterior y menisco lateral, promoviendo así una mejor estabilidad y capacidad funcional, proporcionando una mejoría temprana. y volver a las actividades de la vida diaria de manera satisfactoria.

Palabras clave: Rehabilitación propioceptiva; Ligamento cruzado anterior; Meniscos Tibiales.

\section{Introdução}

De acordo com as citações de Dângelo eFattini (2000), a articulação do joelho é uma estrutura formada pela união de três ossos: fêmur, tíbia e patela (osso sesamóide). Em geral, o joelho consiste em uma complexa estrutura óssea, articular, ligamentar, capsular, meniscal e muscular, sendo capazes de promover estabilidade e mudar de uma estrutura flexível as irregularidades do solo, para uma rígida de sustentação de peso.

A estabilidade do joelho é dada pelo mecanismo contensor dos ligamentos cruzado anterior e posterior, ligamentos colateral medial e lateral, sendo primordiais para uma eficiente locomoção humana. Consideravelmente, o joelho possui a articulação mais complexa do corpo humano, estando bastante susceptível a lesões, o que contribui para a alta incidência de lesões principalmenteao nível do ligamento cruzado anterior (Noronha, 2006).

O Ligamento Cruzado Anterior fixa-se anteriormente na cavidade intercondilar, na depressão anterior à eminência tibial média e se dirige para cima, oblíqua e posteriormente para se inserir no côndilo femoral lateral, sendo tensionado na posição flexionada. Além disso, quando o joelho se movimenta, os ligamentos formam um padrão entrelaçado e por isso são descritos como "cruzados" (Araújo, 2003).

Hoppenfild (2002), afirma que os meniscos são formados por fibrocartilagem que agem como "amortecedores" de impactos, localizados entre o fêmur e a tíbia. O mesmo refere que o menisco pode ser medial ou interno e lateral ou externo.

Silvestre e Lima (2003), confirma que a propriocepção se trata de um feedback dos membros ao sistema nervoso central (SNC), onde o SNC processa estas informações vindas de terminações nervosas especializadas ou de mecanorreceptores que estão localizados na pele, músculos, tendões, cápsulas articulares e ligamentos.

De acordo com as citações de Oliveira et al. (2011), um treinamento proprioceptivo eficiente envolve a consciência da postura, o aprendizado motor, coordenações motoras e equilíbrio e o controle neuromuscular. Esses aspectos são indispensáveis para reestabelecer à funcionalidade visando à necessidade de cada ser humano. 
Portanto, o presente estudo teve como problema: Quais os benefícios da reabilitação proprioceptiva em lesão de ligamento cruzado anterior associado a menisco lateral?

O objetivo geral desta pesquisa foi analisar os benefícios da reabilitação proprioceptiva em lesão de ligamento cruzado anterior associado a menisco lateral, e como objetivos específicos, atualizar os conhecimentos em relação àlesão de ligamento cruzado anterior associado a menisco lateral everificaruma melhor compreensão das estruturasda articulação do joelho e das suas funções.

A importância desta pesquisa para classe fisioterapêutica foi enriquecer e ampliar os conhecimentos teóricos e práticos relacionados à reabilitação proprioceptiva em paciente com lesão de ligamento cruzado anterior associado a menisco lateral.

A pesquisa consiste em uma revisão bibliográfica, verificando uma melhor compreensão das estruturas que o compõem a articulação do joelho, e das suas funções, enfatizando as lesões de ligamento cruzado anterior e menisco lateral, assim como, sua reabilitação.

A referente pesquisa fundamentou-se em referências bibliográficas nacionais e internacionais,periódicos, livros, jornais e revistas científicas.

\section{Metodologia}

O estudo foi realizado sobre o tema através de referências bibliográficas nacionais e internacionais, periódicos, livros, jornais e revistas científicas. As buscas selecionadas foram decorrentes do ano de 1992 a 2011, e que estavam disponíveis para acesso on-line. Os artigos selecionados foram avaliados pelo autor da pesquisa, e aqueles que não se enquadravam no tema proposto foram desconsiderados.

A pesquisa fundamentou-se em uma revisão bibliográfica, verificando uma melhor compreensão das estruturas que o compõem a articulação do joelho, e das suas funções, enfatizando as lesões de ligamento cruzado anterior e menisco lateral, assim como, sua reabilitação.

Portanto, o presente estudo teve como problema: Quais os benefícios da reabilitação proprioceptiva em lesão de ligamento cruzado anterior associado a menisco lateral?

O objetivo geral desta pesquisa foi analisar os benefícios da reabilitação proprioceptiva em lesão de ligamento cruzado anterior associado a menisco lateral, e como objetivos específicos, atualizar os conhecimentos em relação à lesão de ligamento cruzado anterior associado a menisco lateral e verificar uma melhor compreensão das estruturas da articulação do joelho e das suas funções.

A importância desta pesquisa para classe fisioterapêutica foi enriquecer e ampliar os conhecimentos teóricos e práticos relacionados à reabilitação proprioceptiva em paciente com lesão de ligamento cruzado anterior associado a menisco lateral.

\section{Discussão}

A articulação do joelho consiste em três ossos: tíbia proximal, fêmur distal e patela, sendo considerada a maior articulação do corpo. É de natureza ginglimóide e proporciona grande grau de amplitude de movimento. Os movimentos e as estruturas do joelho auxiliam na absorção de impactos, manutenção do equilíbrio e distribuição de forças (Kapandji, 1999). 
Figura 1: Vista anterior dos ossos do joelho.



Fonte: http://www.medsintese.com.br/informacoes_ortopedia_anatomia_joelho.html

O fêmur é o osso mais longo, pesado e mais forte do corpo. Estende-se do quadril até o joelho e representa um quarto da altura do adulto médio. Podemos sentir a extremidade inferior do fêmur ao nível do joelho eextremidade superior está localizada profundamente aos músculos do quadril. Além disso, o fêmur se articula com três ossos: o ilíaco, a patela e a tíbia (Dângelo; Fattini, 2006).

Figura 2: Osso Fêmur.

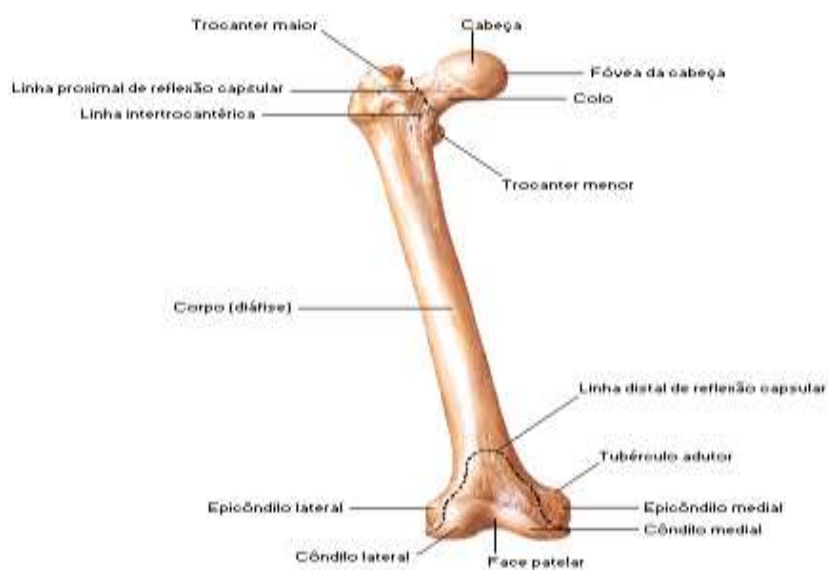

Fonte: www.auladeanatomia.com.

Segundo Dângelo e Fattini (2006), a tíbia é um osso longo fortemente unido pela membrana interóssea que faz parte do esqueleto da perna. Ela é medial e mais espessa que a fíbula, articulando-se com fêmur pela sua extremidade proximal, entretanto, ambos os ossos se articulam ao tálus embora a tíbia seja a responsável direta pela transmissão do peso àquele osso.

De acordo com Lockhart, Hamilton e Fyfe (1992), patela é um osso localizado na parte frontal do joelho, sendo considerado um osso sesamóide, tendo forma triangular, uma base superior e um ápice dirigido inferiormente, estando inserida no tendão do músculo quadríceps da coxa, cuja função principal é atuar potencializando a força dos músculos da parte anterior da coxa para estendendo joelho. 
Figura 3: Osso Patela.
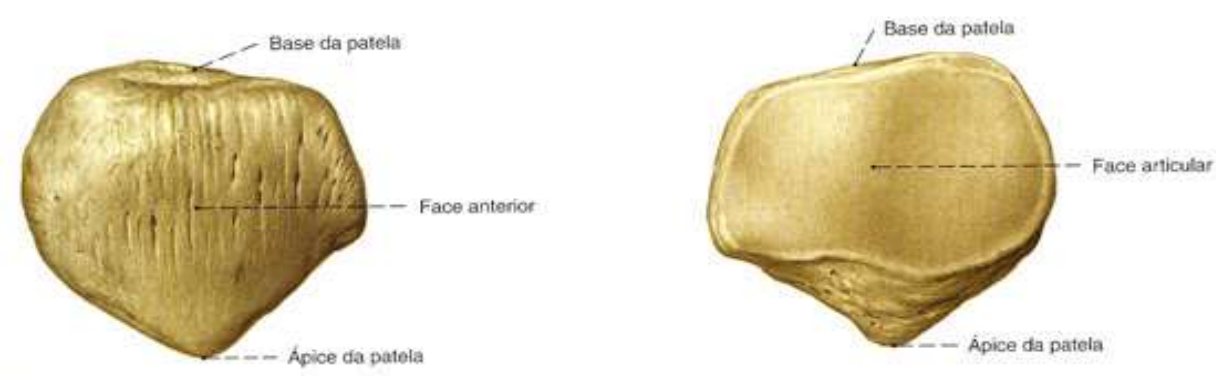

Fonte: Sobotta, J. Atlas de Anatomia Humana. (21a ed.), Guanabara Koogan (2000).

Baseado nas citações de Gross, Fetto e Rosen (2000), a articulação do joelho é uma estrutura formada por três ossos: fêmur, tíbia e patela, por três articulações: articulação tibiofemural medial e lateral, localizada entre a extremidade distal do fêmur e a extremidade superior da tíbia e articulação patelofemural que possibilita mecanismo de extensão do joelho. Em geral, o joelho consiste em uma complexa rede estrutural óssea, articular, ligamentar, capsular e muscular, sendo capazes de promover estabilidade e mudança de direções moldando as irregularidades do solo, para uma estrutura rígida de sustentação de peso.

Segundo Hothschildet al. (2001), a articulação tibiofemural é uma articulação sinovial, onde os côndilos femorais mediais e laterais fazem contato através dos meniscos interpostos à face articular superior da tíbia.

Lockhart, Hamilton e Fyfe (1992), afirmam que o compartimento medial é composto pelo côndilo femoral medial(platô), o menisco medial e a parte medial da tíbia. Em contraste, o compartimento lateral inclui o côndilo lateral femural, o menisco lateral e parte lateral da tíbia.

Conforme Schenck e Heckman (1993), os compartimentos citados acima estãocontidos dentro da mesma cápsula articular.Relatam ainda, que articulação patelofemural é do tipo plana modificada, sendo asuperfície articular lateral da patela mais larga.

Figura 4: Vista anterior das estruturas articulares do joelho.



Fonte: Netter, F. H. Atlas de Anatomia Humana. (2a ed.), Artmed (2000). 
Figura 5: Vista posterior das estruturas articulares do joelho.



Fonte: Netter, F. H. Atlas de Anatomia Humana. (2a ed.), Artmed (2000).

Conforme Hall (2005), a estrutura do joelho permite tanto a sustentação de cargas quanto a mobilidade necessária para a locomoção. Relata ainda que os músculos envolvidos no movimento de extensão do joelho são: reto femoral, vasto lateral, vasto medial e vasto intermédio.

Segundo Campos (2006), a extensão do joelho é um dos principais exercícios que isola o grupo muscular quadríceps femoral.Além disso, o músculo reto femoral é considerado o único biarticular extensor do joelho, onde cruza a articulação do quadril, porém, todos os músculos desse movimento se inserem distalmente no tendão patelar que, por sua vez, se insere na tíbia.

De acordo com Amatuzzi (2004), durante o movimento de flexão do joelho os músculos envolvidos são: Bíceps femoral, semitendíneo e Semimembranáceo. Os músculos ísquiostibiais são flexores de joelho e extensores de quadril, sendo que o bíceps femoral é também um rotador externo, enquanto os demais (semitendíneo, semimembranáceo, sartório e grácil) são rotadores internos.

Biomecanicamentea articulação do joelho é do tipo gínglimo, permitindo o movimento de flexão, extensão e certo grau de rotação.Estaticamente, a estabilidade do joelho é dada pela cápsula articular, ligamentos,meniscos e ossos, portanto, os músculos e tendões são responsáveispela estabilidade dinâmica (Amatuzzi, 2004).

\section{Lesão de ligamento cruzado anterior}

\subsection{Conceitos}

Segundo Tria (2002), a estabilidade medial e lateral da articulação do joelho é dada respectivamente pelo mecanismo contensor dos ligamentos colaterais medial e lateral. Os ligamentos cruzados anterior e posterior são importantes para estabilidade ântero posterior e rotacional do joelho, estando localizados no centro da articulação.

No entendimento de Cailliet (2001), a lesão do ligamento cruzado anterior ocorre quando há uma lesão rotacional forçada externamente emvalgo. Afirma ainda que a lesão que é causada por esse mecanismo está associada com lesão de outra estrutura, tais como o ligamento colateral medial.

Segundo Kisner (1998), após o trauma, os ligamentos do joelho podem ser estirados ou rompidos, podendo resultar em ruptura parcial ou total de um ou mais ligamentos. Vale ressaltar que geralmente levaalgumas horas para haverderrame articular e quando este ocorre, o movimentofica restrito.

Já para Amatuzzi (2004), a lesão do ligamento cruzado anterior é a lesão de maior ocorrência na articulação do joelho, encontrada frequentemente na população ativa, sendo ocasionadas por forças que distendem algumas ou todas as fibras do ligamento além do seu limite de elasticidade, resultando em diferentes graus de ruptura. 
Figura 6: Posicionamento do ligamento cruzado anterior.

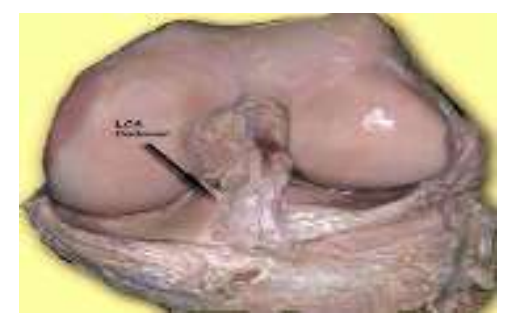

Fonte: Castro (2013).

Figura 7: Lesão do ligamento cruzado anterior.



Fonte: http://www.clinicadeckers.com.br/html/orientacoes/ortopedia/024_dist_lca.html

Segundo Castropril (1999), os traumas ocorrem devido a uma ruptura das fibras,podendo ser parcial ou total. Tal lesão é comum em esportistas quando estes realizammovimentos de pivôs (giros). Inúmeras vezes estas lesões são decorrentes de despreocupação quanto aos programas de prevenção.

Conforme Vilardi (2004), estudos realizados na Dinamarca demonstraram que a cada 10 mil indivíduos com idade superior a 50 anos, três são portadores de lesão do ligamento cruzado anterior. Em outro estudo populacional nos Estados Unidos, afirmou que são realizadas aproximadamente 70 mil reconstruções ligamentares do joelho por ano.

\subsection{Sinais e Sintomas}

Os sinais e sintomas das lesões ligamentares do joelho variam de acordo com o mecanismo causador, a gravidade da lesão, os tecidos acometidos e a extensão do acometimento. Geralmente são evidentes graus variáveis de dor, derrame articular, insegurança e incapacidade funcional (Amatuzzi, 2004).

Para Andrade e Lemos (2001), quando ocorre o trauma o joelho bloqueia, gerando um processo doloroso, edema local, onde consequentemente limita a amplitude de movimento.Os autores afirmam que após pesquisas, verificou-se que cerca de 75\% apresentou hemartrose associado a lesão do ligamento cruzado anterior.

Os sinais e sintomas da lesão do ligamento cruzado anterior variam de acordo com o grau da lesão. Geralmente, a lesão grau I, ocorre um estiramento com mínima presença de edema, pouca dor e ainda é capaz de ajudar a manter a estabilidade da articulação do joelho. Em relação ao grau II, o ligamento estende de modo a gerar alguma instabilidade no joelho. Este é muitas vezes referida como uma ruptura parcial do ligamento. Para a lesão grau III, ocorre uma lesão completa do ligamento. O ligamento é dividido em duas partes, e a articulação do joelho é instável em um determinado movimento (Brown; Neumann, 1996). 


\subsubsection{Classificação da lesão}

Segundo Hatcher (2005), os lesionados são considerados "entorses" e classificam-se em agudas e crônicas. As lesões agudas, por sua vez, são subdivididas em três graus, conforme uma escala de gravidade.

- Grau I: trata-se de uma lesão leve com um estiramento ligamentar. Caracteriza-se por pouca ou nenhuma perda funcional, com estabilidade da articulação do joelho íntegra.

- Grau II: Refere-se à lesão moderada com ruptura parcial doligamento, sendo caracterizada por comprometimento funcional, dor e edema e alguma instabilidade no joelho.

- Grau III: Ocorre uma ruptura completa do ligamento cursando com perda de integridade ligamentar. Caracterizada por edema acentuado, déficit de funcionalidade e limitações de movimento.

As lesões crônicas resultam da falta ou do insucesso na reabilitação das lesões agudas, podendo resultar também de doenças degenerativas articulares, que enfraquecem os ligamentos. São geralmente classificados em dois tipos, com características diferentes: a instabilidade e a mecânica (Herbert; Xavier, 2003).

O mecanismo de lesão do ligamento cruzado anterior ocorre por um trauma rotacional. Nesses casos, o corpo gira em rotação externa com o pé fixo no chão. Outro mecanismo, porém, mais raro, é a hiperextensão do joelho sem apoio, chamado chute no ar, que determina a lesão isolada do ligamento (Camanho, 1996).

\section{5 - Lesão Menescal}

\subsection{Conceitos}

Segundo as citações de Ellenbecker (2002), os meniscos são estruturas internas do joelho, localizadas entre o fémur e a tíbia. Têm composição fibrocartilaginosa, um formato triangular e atuam como amortecedores de impactos.Os meniscos têm como função proteger a cartilagem, ajudar na congruência, na estabilidade e na irrigação articular.

De acordo com Amatuzzi (2004), os meniscos podem ser mediais ou lateral e ambos são aderidos à cápsula articular. Afirma que são duas peças em forma de cunha, resistentes e elásticos para ajudar a amortecer a articulação e mantê-la estável.

Hoppenfild (2002) confirma que além de integrar melhor a superfície articular do joelho, os meniscos auxiliam na transmissão de forças na descarga de peso, melhor lubrificação e facilitam o movimento de flexo-extensão. Considera que o menisco medial tem forma de "C" e o menisco lateral é semelhante a um anel em forma de "O".

Figura 8: Principais estruturas da articulação do joelho.

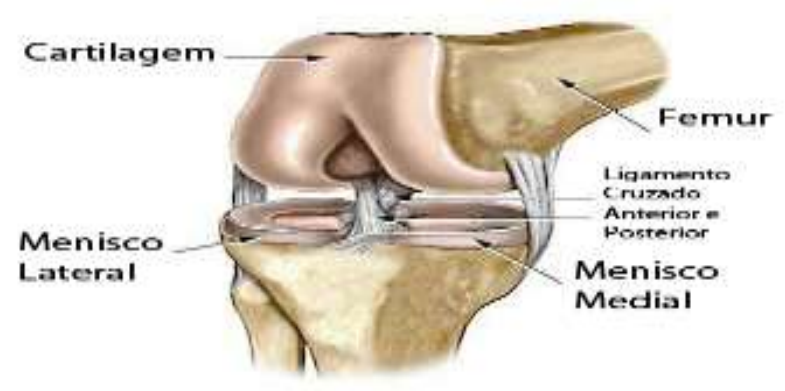

Fonte: http://www.amato.com.br/consultorio-medico/content/dor-nos-joelhos

De acordo com kapandji (1999), as lesões meniscais estão entre as mais comuns da articulação do joelho. Os atletas, particularmente aqueles que praticam esportes de contato, estão em risco de rupturas meniscais. No entanto, qualquer pessoa em qualquer idade pode lesar um menisco. 
Segundo Amatuzzi (2004), a lesão é bastante rara em crianças com idade abaixo de 12 anos, mas vem aumentando com a precocidade do início de atividades esportivas competitivas em faixas etárias pré-adolescentes. No adulto, é geralmente associado a trauma e constantemente o esportivo. Com a idade aproximadamente entre 55 e 60 anos, os indivíduos são mais propensos a ter lesão meniscal degenerativa.

\subsection{Sinais e Sintomas}

As citações de Kapandji (2000) e Magee (2002), afirmam que as lesões do menisco costumam ser acompanhadas por um "estalido", no momento em que se dá a lesão, pelo surgimento de dor e pela produção de uma inflamação. No entanto, a sintomatologia varia de acordo com a gravidade da lesão, a extensão do seu acometimento e os tecidos acometidos.

Os lesionados tendem a informar a data do início dos sintomas e a relacionam com o trauma. O paciente refere um quadro inicial rico em sinais e sintomas, seguido em geral de períodos de acalmia. Entretanto, cursa com dor, edema, rigidez, sensação de bloqueio do joelho e instabilidade articular (Hoppenfild, 2002).

Segundo Potter (2006), após a realização da ressonância magnética a lesão do menisco é classificada em 3 graus de acordo com sua gravidade. Vale destacar que em todos os graus apresentam o hipersinal intrameniscal.

> Grau 1: É considerada umalesão intrasubstancial do menisco e não se estende a superfície.

$>$ Grau 2:É a lesão do menisco que se estende a uma das superfícies, sendo a superior.

> Grau 3:Refere-se a uma lesão que se estende as duas superfícies, tanto a superior quanto a inferior.

\section{Reabilitação Proprioceptiva}

De acordo com Silvestre e Lima (2003), a reabilitação proprioceptiva ou propriocepção tem por definição a capacidade inconsciente de sentir o movimento e a posição de uma articulação no espaço caracterizada por aferências neurais originadas de mecanorreceptoresque estão localizados na pele, músculos, tendões, cápsulas articulares e ligamentos.

Segundo as citações de Araújo, Merlo e Moreira (2003), propriocepção refere-se a um tipo de feedback dos membros ao sistema nervoso central (SNC). Afirma que cada região possui seus mecanorreceptoresespecíficos e que os estímulos proprioceptivos tem um sentido mais amplo, abrangendo e incluindo o controle neuromuscular.

A propriocepção é o termo que descreve umconjunto de informações e mecanismos que contribuem paraa percepção do próprio corpo, a estabilidadearticular proporcionando a sensação de posição e movimento dos próprios membros, sem o uso da visão, incluindo a consciência das mudanças no equilíbrio, além de englobar as sensações de posição articular (Kandell; Schwartz; Jessel, 2003).

Gustavo, Leonardo e Maria (2009), afirmam que a propriocepção se trata de uma informação da articulação para o cérebro dando consciência das condições de posicionamento articular tanto estático (parado), quanto dinâmico (em movimento).

Para Leporace (2009), os mecanorreceptoressão receptores sensoriais que enviam ao sistema nervoso central (SNC) as informações proprioceptivas por vias aferentes promovendo a estabilização articular.Contribuem para a sensação de toque, pressão e de vibração, sendo que a maioria dos mecanorreceptores consiste em fibras aferentes de baixo limiar. 
Figura 9: Feedback na propriocepção.

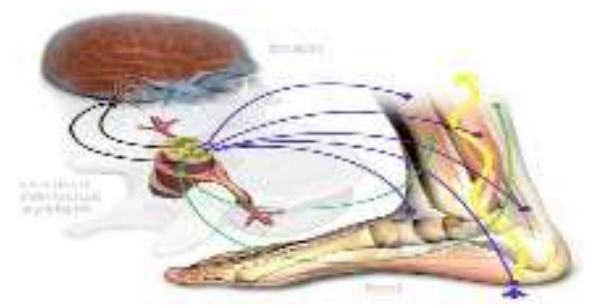

Fonte: http://juliopastore.blogspot.com.br/2010/05/propriocepcao.html

De acordo com Myeret al. (2006), uma reabilitação orientadabaseia-se numa série de procedimentos fisioterapêuticos com a finalidade de restaurar a função ou modificar os conhecimentos da percepção com um novo programa neuromotor. Para isso, são avaliadosforça muscular, estabilidade funcional do joelho, equilíbrio, controle postural, resistência,agilidade e gestos esportivo ou referenteàs atividades diárias, proporcionando precocemente o retorno às atividades desejadas de forma satisfatória.

\section{1 treinamento proprioceptivo}

De acordo com Fitzgerald (1997), o treinamento proprioceptivo é utilizado para proporcionar estabilidade na articulação do joelho, reações de mudanças de posicionamento e defesa, dessa forma, influenciando com maior segurança possível o retorno precoce as atividades desejadas.

Para Ferreira (2009), os treinamentos funcionais com a utilização de alguns recursos facilitam a propriocepção. As escadas e rampas, plataformas instáveis, cama elástica, balancinho, disco proprioceptivo, tabuas proprioceptivas, proporcionam maiorativação do sistema proprioceptivo estático e dinâmico. Além disso,auxilia na posição corporal e equilíbrio, promovendo uma coordenação com qualidade.

Figura 10: Escada e Rampa para propriocepção.

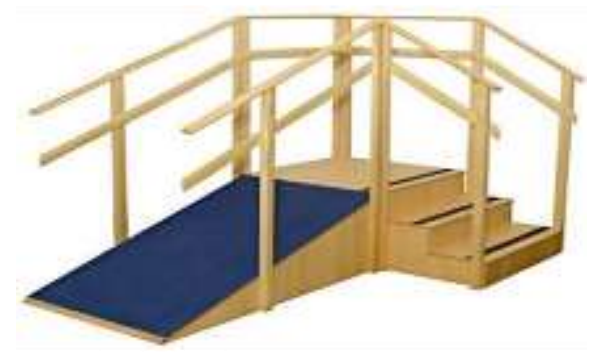

Fonte: http://www.hbfisio.com.br/popup.php?img=4d0c9d01c0f74.jpg

Figura 11: Tábuas Proprioceptivas.


Fonte: www.loja.casadomedico.com.br 
Figura 12: Cama elástica e balancinho respectivamente.
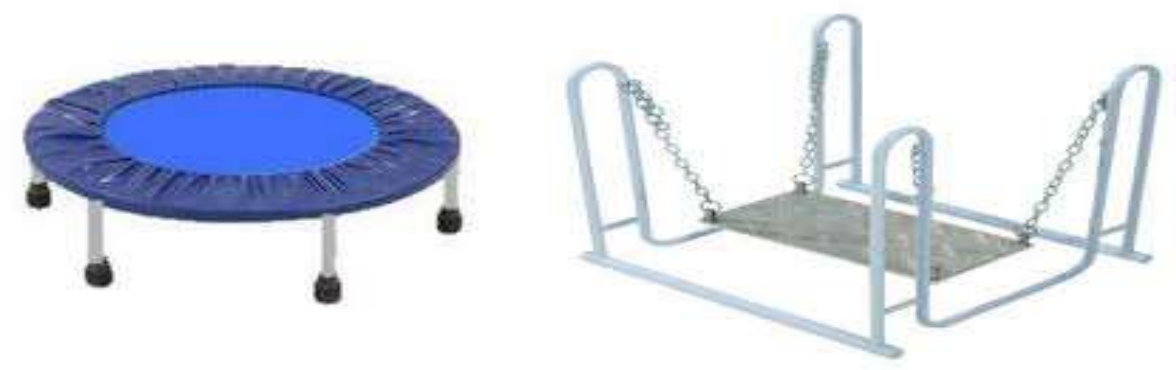

Fonte: megafisio.com.br

Figura 13: Disco Proprioceptivo.

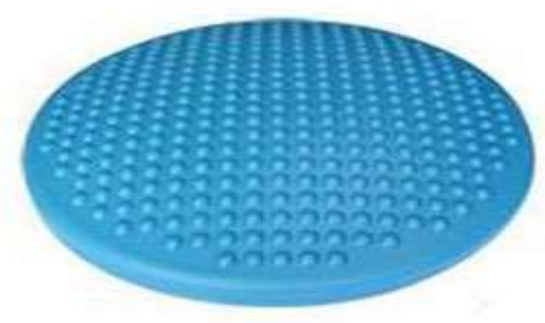

Fonte: www.fisiostore.com.br

\section{Resultados}

No entendimento de Cailliet (2001), a lesão do ligamento cruzado anterior ocorre quando há uma lesão rotacional forçada externamente emvalgo. Afirma ainda que a lesão que é causada por esse mecanismo está associada com lesão de outra estrutura, tais como o ligamento colateral medial.

Já para Amatuzzi (2004), a lesão do ligamento cruzado anterior é a lesão de maior ocorrência na articulação do joelho, encontrada frequentemente na população ativa, sendo ocasionadas por forças que distendem algumas ou todas as fibras do ligamento além do seu limite de elasticidade, resultando em diferentes graus de ruptura.

Segundo Potter (2006), após a realização da ressonância magnética a lesão do menisco é classificada em 3 graus de acordo com sua gravidade. Vale destacar que em todos os graus apresentam o hipersinal intrameniscal e a pior lesão do menisco associa-se ao grau III, pois se refere a uma lesão que se estende as duas superfícies, tanto a superior quanto ainferior.

Kapandji (2000) e Magee (2002), afirmam que as lesões do menisco costumam ser acompanhadas por um "estalido" independente da gravidade, no momento em que se dá a lesão, pelo surgimento de dor e pela produção de uma inflamação. No entanto, a sintomatologia varia de acordo com a gravidade da lesão, a extensão do seu acometimento e os tecidos acometidos.

De acordo com Silvestre e Lima (2003), a propriocepção tem por definição a capacidade inconsciente de sentir o movimento e a posição de uma articulação no espaço caracterizada por aferências neurais originadas de mecanorreceptores que estão localizados na pele, músculos, tendões, cápsulas articulares e ligamentos. 
Neste mesmo sentido, para Ferreira (2009), os treinamentos funcionais além de auxiliar na posição corporal e equilíbrio, promove uma coordenação com qualidade. Dessa forma, a utilização de alguns recursos facilita a propriocepção, como: escadas e rampas, plataformas instáveis, cama elástica, balancinha, disco proprioceptivo, tabuas proprioceptivas, proporcionam maior ativação do sistema proprioceptivo tanto estático quanto dinâmico.

De acordo com os autores citados acima, o treinamento funcional destaca-se como uma forma de intervenção fisioterapêutica que apresenta evidências clínicas para uso em lesões de ligamento e menisco com o objetivo de proporcionar estabilidade na articulação do joelho, reações de mudanças de posicionamento e defesa, capacidade funcional, proporcionando precocemente maior segurança e retorno as atividades da vida diária.

Portanto, um protocolo adequado é um dos principais fatores para a recuperação funcional da lesão do ligamento cruzado anterior e menisco lateral. Dessa forma, utilizando os planos instáveis, melhora a resposta de reação neuromuscular. Vale ressaltar que esta fase de tratamento, ocorre após ausência ou diminuição da sintomatologia inicial, com amplitude de movimento e força muscular preservada.

\section{Conclusão}

Com base no estudo realizado, constatou-se que de acordo com os autores investigados, os treinamentos proprioceptivos são eficientes na reabilitação da lesão de ligamento cruzado anterior e menisco lateral, promovendo assim, melhora da estabilidade e capacidade funcional, proporcionando precocemente maior segurança e retorno as atividades da vida diária de forma satisfatória.

Concluiu-se que a propriocepção se tornou fundamental para reabilitação do joelho, contribuindo para eficiência da habilidade e confiança em qualquer atividade que exija a utilização da articulação do joelho.

Entretanto, deve-se ressaltar que, em relação aos privilégios de que gozam os autores das referências selecionadas nesta revisão de literatura, a escolha de teorias e métodos para realizar inovações pode ser considerada uma abordagem promissora para o desenvolvimento do conhecimento atual. Neste tópico, portanto, recomenda-se o uso de métodos qualitativos em pesquisas futuras e a adoção de teorias mais profundas que possam refletir sobre o respectivo assunto.

\section{Referências}

Andrade, M. A. P., \& Lemos, w. G. (2001). Hemartrose. Revista do joelho, 1(1),15-17.

Amatuzzi, M. M. (2004). Articulação central dos membros inferiores: Joelho. Editora Roca.

Araújo, A. D. S., Merlo, J. R. C., \& Moreira, C. (2003). Reeducação neuromuscular e proprioceptiva em pacientes submetidos à reconstrução do ligamento cruzado anterior. Revista Brasileira de Fisioterapia, 4(3), 217-221.

Brown, D. E., \& Neumann, R. D. (1996). Segredos em ortopedia, respostas necessárias ao dia-a-dia em rounds, na clínica, em exames orais e escritos. Porto Alegre: Editora Artes Médicas.

Caillet, R. (2001). Dor no Joelho. (3a ed.), Editora Artmed.

Camanho, G. L. (1996). Patologias do joelho.: Editora Sarvier.

Campos, M. A. (2006). Biomecânica da musculação. (3a ed.), Editora Sprint.

Castropil, W. (1999). Medicina Esportiva. <www.castropil.com.br>

Dangelo, J. G., \& Fattini, C. A. (2000). Anatomia humana sistêmica e segmentar: para o estudante de medicina. (2a ed.), Editora Atheneu.

Dangelo, J. G., \& Fattini, C. A. (2006). Anatomia humana sistêmica e segmentar. (2a ed.), Editora Atheneu.

Ellenbecker, T. S. (2002). Reabilitação dos ligamentos do joelho. Editora Manole.

Ferreira, L. A. B. (2009). Análise da atividade eletromiográfica dos músculos do tornozelo em solo estável e instável com olhos abertos e fechados. Dissertação de Mestrado (Mestre em Engenharia Biomédica) -Universidade do Vale do Paraíba, São José dos Campos, SP. <http://www.lume.ufrgs.br/bitstream/handle/10183/14412/000666417.pdf?sequence=1> 
Fitzgerald, G. K. (1997). Open versus kinetic chain exercises: Issues in Rehabilitation After Anterior Cruciate Ligament Reconstructive Surgery. Journal of Physical Therapy Science, 77 (12), 1-8.

Gross, J., Fetto, J., \& Rosen, E. (2000). Exame Musculoesquelético. Editora Artmed.

Gustavo, L., leonardo, M., \& Maria, M. M. S. (2009). Importância do treinamento da propriocepção e do controle motor na reabilitação após lesões musculoesqueléticas. Acta Fisiátrica.

Hall, S. J. (2005). Biomecânica Básica. Tradução de Giuseppe Taranto. (4a ed.), Editora Guanabara Koogan.

Hatcher, J. (2005). An investigation to examine the inter-tester and intra-tester reliability of the Rolimeter knee tester, and its sensitivity in identifying knee joint laxity. Journal of Orthopaedic Research.

Herbert, S., \& Xaier, R. (2003). Ortopedia e traumatologia. (3a ed.), Editora Artmed.

Hoppenfild, S. (2002). Propedêutica Ortopédica. Editora Atheneu.

Hothschild, H. et al. (2001). Atualização Terapêutica. (20a ed.), Editora Artes Médicas.

Kandel, E. R., schwartz, J. H., \& Jessel, T. M. (2003). Princípios da Neurociência. (4a ed.), Editora Manole.

Kapandji, A. I. (1999). Fisiología Articular. (5a ed.), Editora Manole.

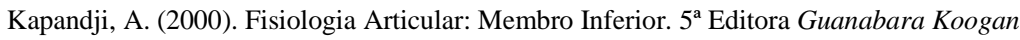

Kisner, C., \& Colby, L. A. (1998). Exercícios Terapêuticos: Fundamentos e Técnicas.: Editora Manole.

Leporace, G. (2009). Importância do treinamento da propriocepção e do controle motor na reabilitação após lesões músculo esqueléticas._Acta Fisiátrica, 16(3).

Lockhart, R. D., Hamilton, G. F., \& Fyfe, F. W. (1992). Anatomia humana. México: Editorial Interamericana.

Myer, G. D., paterno, M. V., Ford, K. R., Quatman, C. E., \& Hewett, T. (2006). Rehabilitation After Anterior Cruciate Ligament Reconstruction: Criteria-Based Progression Through the Return to Sport Phase. Journal of Orthopaedic \& Sports Physical Therapy, 36(6): 385-402.

Netter, F. H. (2000). Atlas de Anatomia Humana. (2a ed.), Editora Artmed.

Oliveira, G. H. et al. (2011). Analise Comparativa entre dois métodos de treinamento sensório - motor em jovens atletas de futebol. Disponívelem:http://www.perspectivasonline.com.br/revista/2011vol5n17/volume5(17)artigo14.pdf

Potter, H. L. (2006). Magnetic Resonance Imaging of Articular Imaging: Trauma, Degeneration and Repair. Sports Med.

Schenck, R. C., \& Heckman, J. D. (1993) ClinicalSymposia (lesões de joelho). 45(1).

Silvestre, M. V., \& Lima, W. C. (2003). Importância do treinamento proprioceptivo na reabilitação de entorse de tornozelo. Fisioterapia em Movimento, 16(2), 27- 34 .

Tria, A. J. (2002) Lesões Ligamentares do Joelho. Editora Revinter. 